\section{Incidental Total Necrosis of a Successful Flap Due to a Secondary Operation after One Year}

Sang Wha Kim ${ }^{1}$, Young Hun Kwon ${ }^{2}$, Youn Hwan Kim ${ }^{2}$

${ }^{1}$ Department of Plastic and Reconstructive Surgery, The Catholic University of Korea College of Medicine, Seoul; ${ }^{2}$ Department of Plastic and Reconstructive Surgery, Hanyang University College of Medicine, Seoul, Korea

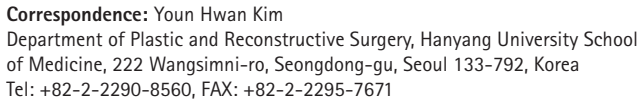

No potential conflict of interest relevant to this article was reported.

Received: 24 Jul 2013・Revised: 30 Sep 2013・Accepted: 2 Oct 2013 pISSN: 2234-6163 • elSSN: 2234-6171

http://dx.doi.org/10.5999/aps.2014.41.3.294 • Arch Plast Surg 2014;41:294-296 Copyright (C) 2014 The Korean Society of Plastic and Reconstructive Surgeons This is an Open Access article distributed under the terms of the Creative Commons Attribution Non-Commercial License (http://creativecommons.org/licenses/by-nc/3.0) which permits unrestricted non-commercial use, distribution, and reproduction in any medium, provided the original work is properly cited.

Developments in microsurgical techniques and instruments have enabled the high success rate of microvascular tissue transfers. Initially, the survival of a free flap is dependent on its vascular pedicle, and the failure of flaps generally occurs within seven days of surgery. Several experimental studies have shown that pedicles can be ligated 5 to 10 days after the operation. Hence, at that time, the flap can be safely divided, and its survival can be ensured [1]. In addition, clinical studies have recommended that flaps can be safely divided between 7 and 21 days after surgery [2]. In this article, we report a case of the total loss of a flap after a secondary operation that was performed one year after successful reconstruction using a latissimus dorsi muscle flap.

A 68-year-old male presented with a chronic wound on his left leg. The patient had suffered an open fracture of his left tibia 15 years previously due to a fall. Radiologic findings revealed non-union of the tibia, and osteomyelitis was suspected. The orthopedic surgeon debrided the osteomyelitic bone, and we performed a reconstruction using a latissimus dorsi muscle free flap, which was $10 \mathrm{~cm} \times 8 \mathrm{~cm}$ in size, and a split thickness skin graft to cover the wound. The pedicle was located in the middle of the flap, and a posterior tibial vessel was used as the recipient vessel. The reconstruction was successful without complications such as partial necrosis, color change, or congestion (Fig. 1). Eighteen months later, the debrided bone with the bone defect seemed to be unstable, and the orthopedic surgeon planned an open reduction and internal fixation with a plate and free bone graft. A skin incision was made at the lateral margin of the flap, and the operation was conducted with a tourniquet applied. The location of the pedicle was marked using a hand Doppler before the operation, and no injury was found in the pedicle during dissection. There was no evidence that the main pedicle was bleeding after the tourniquet was removed. Immediately after the operation, the flap displayed a partial change of skin color (Fig. 2), and after three weeks, it became totally necrotic. We decided to discard the flap (Fig. 3) and reconstructed the defect with an anterolateral thigh flap, which was $12 \mathrm{~cm} \times 9 \mathrm{~cm}$ in size, by using the posterior tibial artery as the recipient vessel (Fig. 4). Three weeks later, the orthopedic surgeon removed the plate and the screws. A skin incision was made at the lateral margin of the flap. The method by which the perforator of the flap was marked was the same as
Fig. 1.

(A) A 68-year-old male presented with a chronic wound on his left leg. Radiologic findings revealed non-union of the tibia, and osteomyelitis was suspected. (B) The orthopedic surgeon debrided the osteomyelitic bone, and we performed a reconstruction using a latissimus dorsi muscle free flap and a split thickness skin graft to cover the wound.
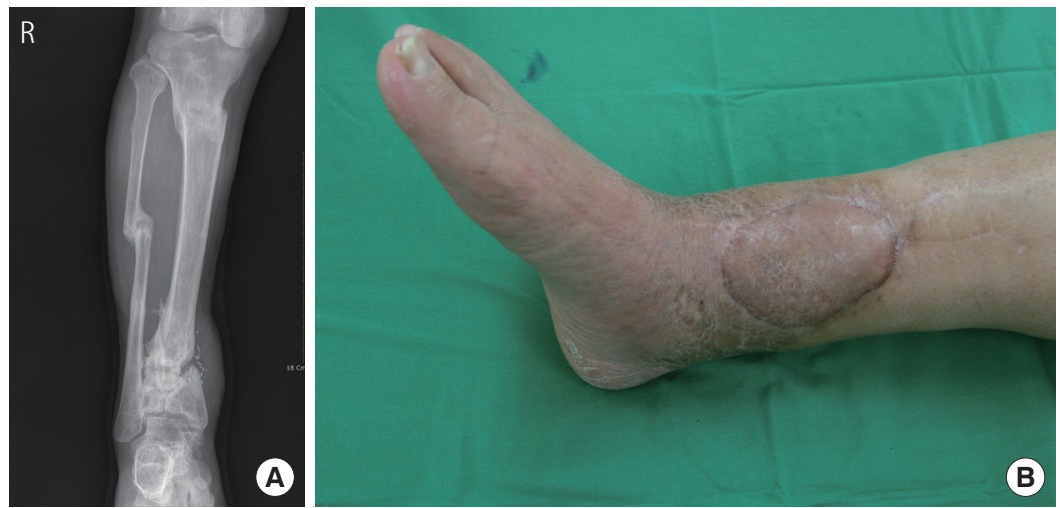


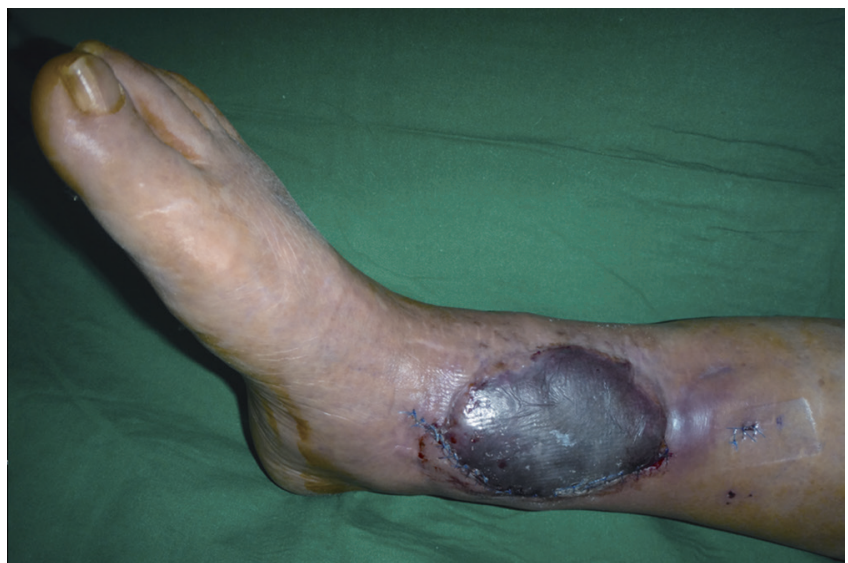

Fig. 2.

Immediately after the operation, the skin of the flap partially changed

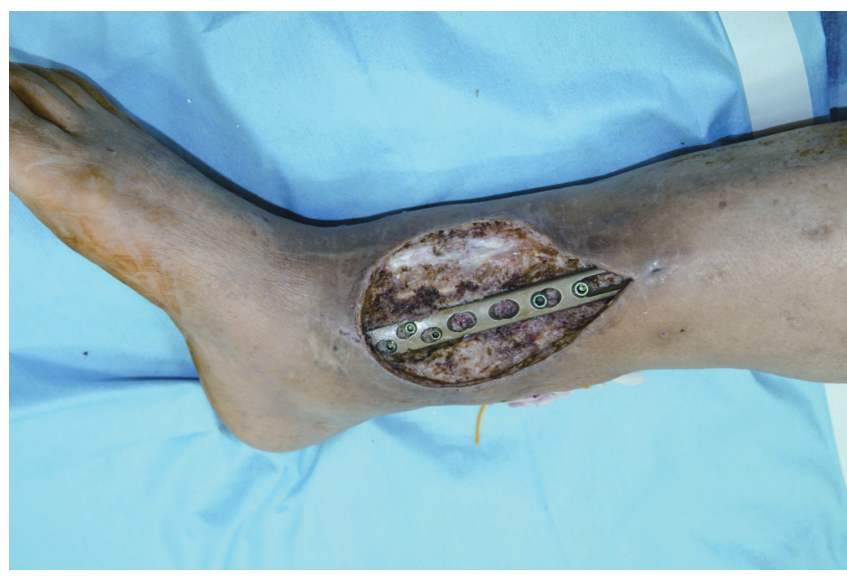

Fig. 3.

The flap was totally useless and hence, was discarded. before; the operation was successful, and no injury of the main pedicle during tourniquet application was observed. After the operation, the flap survived without complication, and the wound healed completely.

After successful reconstruction by microvascular free tissue transfer, additional procedures are often performed. They include flap division to deal with multiple defects, liposuction for volume reduction, and debulking procedures for contouring. In our case, an incision was made at the flap margin, and the flap was lifted since the orthopedic surgeon required a secondary operation. Such additional procedures are made possible by neovascularization across the free flap from the surrounding tissue and from the wound bed; therefore, the flap is not totally dependent on the original pedicle for vascularity.

Experimental studies have demonstrated that neovascularization develops within 7 to 10 days [1]. On the other hand, there are a few case reports of flap failure as late as 16 months postoperatively [3], which suggests that there can be a significant blood supply from the anastomosed vessel even 1 or 2 years after surgery [4].

From these studies, it seems likely that most free flaps are neovascularized around seven days after the operation. However, several factors can lead to unpredicted late flap failure. Flaps may depend longer on the main vascular pedicle in patients with compromised recipient beds. Moreover, when the wound is chronic, the patient has peripheral vascular disease that affects the marginal blood supply, there is a subclinical infection, or the wound has received radiation treatment, then neovascularization of the flap is inhibited, development of a collateral circulation from the surrounding tissues or from the wound bed is hindered, and the flap remains dependent on the main pedicle [5]. In our case, the patient had suffered from a chronic wound for 15 years, which led to fibrous scarring that repeatedly healed and worsened, disrupting the peripheral vascularity.

It is well known that smoking affects the survival of free flaps and replantations by compromising vascularity. Our patient was a heavy smoker and continued smoking even after the operation. This may have affected neovascularization or capillary perfusion, even though the flap survived with the blood supply from the main pedicle.

In addition, although the skin incision was made at the lateral border of the flap, the flap itself was lifted completely, leaving only the opposite margin intact. Moreover, the flap might have been pulled and stretched during the operation to obtain a better view of the tibia. The previously formed neovascularization from the skin incision site and the wound bed may have been cut off, and the internal fixation with a plate and bone graft may have worsened the state of the wound bed. A plate and bone graft beneath a flap pushes on the flap, increasing the tension at its margin, and this may have affected the vascularity of the flap.

Although most free flaps are believed to be neovascularized around seven days after surgery, in one study, no new vessel formation was observed in the margins of the flap after the occlusion of the original anastomosis, and there was significant blood flow into the flap through the anastomotic vessels even after 1 to 2 years [4]. Therefore, additional procedures after free flap surgery should be 


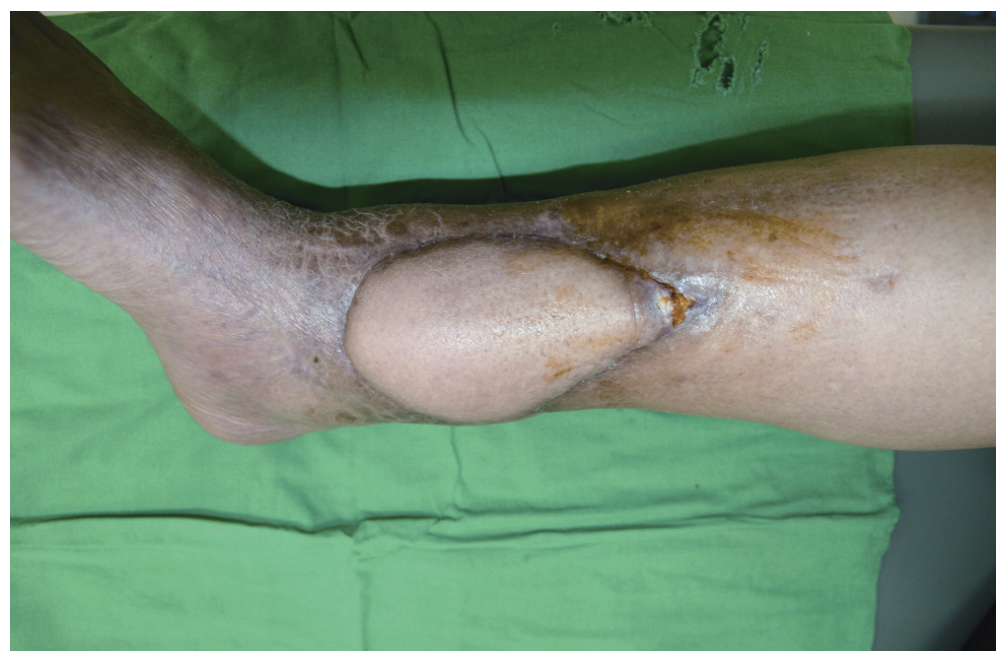

Fig. 4 .

We reconstructed the defect with an anterolateral thigh flap using the posterior tibial artery as the recipient vessel.

\section{Surgical Removal of Intraneural Perineurioma Arising in the Brachial Plexus Using an Interfascicular Dissection Technique}

Jae-Hyun Chung, Seong-Ho Jeong, Eun-Sang Dhong, Seung-Kyu Han

Department of Plastic Surgery, Korea University Guro Hospital, Korea University College of Medicine, Seoul, Korea

Correspondence: Seong-Ho Jeong

Department of Plastic Surgery, Korea University Guro Hospital, Korea University College of Medicine, 148 Gurodong-ro, Guro-gu, Seoul 152-703, Korea

Tel: +82-2-2626-3133, Fax: +82-2-852-7484

Email: surgilearn@korea.ac.kr

This article was presented as a poster at The 3rd Research and Reconstructive Forum on May 9-10, 2013 in Daegu, Korea

No potential conflict of interest relevant to this article was reported.

Received: 21 Jul 2013 • Revised: 11 Sep 2013 • Accepted: 27 Sep 2013 pISSN: 2234-6163・ elSSN: 2234-6171

http://dx.doi.org/10.5999/aps.2014.41.3.296• Arch Plast Surg 2014;41:296-299

Copyright (C) 2014 The Korean Society of Plastic and Reconstructive Surgeons

This is an Open Access article distributed under the terms of the Creative Commons

Attribution Non-Commercial License (http://creativecommons.org/licenses/by-nc/3.0)

which permits unrestricted non-commercial use, distribution, and reproduction in any medium, provided the original work is properly cited.

secondary operation was performed 18 months after successful reconstruction using a latissimus dorsi muscle flap. There is controversy concerning flap neovascularization, and many factors can compromise flap vascularity including the flap itself, patient comorbidities, and the wound condition. Given these risks, additional procedures affecting the flap should be performed with considerable care, with attention paid to flap vascularity.

\section{References}

1. Young CM. The revascularization of pedicle skin flaps in pigs: a functional and morphologic study. Plast Reconstr Surg 1982;70:455-64.

2. Klingenstrom P, Nylen B. Timing of transfer of tubed pedicles and cross-flaps. Plast Reconstr Surg 1966;37:1-

12.

3. Bhat W, Wiper JD, Platt AJ. Delayed autologous free anterolateral thigh flap failure. J Plast Reconstr Aesthet Surg 2011;64:420-1.

4. Kumar K, Jaffe W, London NJ, et al. Free flap neovascularization: myth or reality? J Reconstr Microsurg 2004;20:31-4.

5. Salgado CJ, Smith A, Kim S, et al. Effects of late loss of arterial inflow on free flap survival. J Reconstr Microsurg 2002;18:579-84.
A perineurioma is an uncommon neoplasm defined as a peripheral nerve sheath tumor composed exclusively of neoplastic perineurial cells, and its two main forms are intraneural and extraneural types [1]. Intraneural perineuriomas often cause motor or sensory deficits [2] and seem to be less common than extraneural ones. As intraneural perineurioma is rarely known to arise in the brachial plexus, principles of its surgical treatment have not been formulated thus far. Here, we report a rare case of surgical removal of intraneural perineurioma arising in the brachial plexus using a microsurgical interfascicular dissection technique for functional preservation. The technical feasibility and advantages of this method are discussed in this report.

A 58-year-old woman was referred for the surgical management of a right axillary mass that was incidentally noted on ultrasonography. The tumor had already been diagnosed as a spindle cell tumor from an ultrasound-guided biopsy. Spindle cell tumors are soft tissue sarcomas, which require a histopathological examination because of the limited material availability in the needle aspirates [3]. To rule out malignant 